\title{
The Impact of Cysteine-Rich Intestinal Protein 1 (CRIP1) on Thyroid Carcinoma
}

\author{
Hong-guang Lia Li-hong Zhao ${ }^{b}$ Zhen-hua Zhanga Jun-zhao Liua Ke Renc \\ Shao-ying Lic Zi-jie Su \\ ${ }^{a}$ Department of Thyroid Surgery, Henan Provincial People's Hospital, Zhengzhou bentral Sterile Supply \\ Department, Henan Provincial People's Hospital, Zhengzhou 'Department of General Surgery, Henan \\ Provincial People's Hospital, Zhengzhou, China
}

\section{Key Words}

Thyroid carcinoma $\bullet$ CRIP1 $\bullet$ G1 arrest • Migration $\bullet$ Invasion

\begin{abstract}
Background/Aims: CRIP1 (cysteine-rich intestinal protein 1) has been found in several tumor types; however, its prognostic impact and role in cellular processes, particularly in thyroid carcinoma, are still unclear. Methods: To elucidate the prognostic impact of CRIP1, we analyzed tissues from 58 primary invasive thyroid carcinomas using immunohistochemistry. Western blotting was performed to investigate CRIP1 protein expression in the thyrocyte cell line Nthyori 3-1 and four different thyroid carcinoma cell lines, K1, TPC-1, TT, and SW579. Endogenous expression of CRIP1 was suppressed using a siRNA (si-CRIP1). The 3-(4,5-dimethylthiazol-2-yl)2,5-diphenyltetrazolium bromide assay was used to investigate cell viability. Flow cytometric analysis was used to detect cell cycle progression and cell apoptosis. The effects of silencing CRIP1 on cell migration and invasion were detected using the transwell assay. Results: The immunohistochemistry results showed that CRIP1 was overexpressed in thyroid carcinoma. CRIP1 expression was associated with tumor size, TNM stage, and lymphatic metastasis, but not with age, gender, and tumor location. In addition, the expression of CRIP1 in K1, TPC-1, TT, and SW529 cells was higher than that in the Nthy-ori 3-1 cells. The highest expression was observed in the SW579 and TT cells. Furthermore, silencing CRIP1 inhibited the proliferation, migration, and invasion of thyroid carcinoma cell lines SW579 and TT. We also found that silencing CRIP1 induced G1 arrest and apoptosis of thyroid carcinoma cell lines SW579 and TT. Conclusion: In conclusion, CRIP1 acts as an oncogene in the cell proliferation, migration, and invasion processes of thyroid carcinoma. CRIP1 may serve well as an independent prognostic marker with significant predictive power for use in thyroid carcinoma therapy.

\section{Introduction}

Thyroid carcinoma is the most common type of malignant thyroid tumor, which develops from the thyroid epithelial cells [1]. It is mainly divided into four types according H.-g. Li and L.-h. Zhao contributed equally to this work. 


\section{Cellular Physiology Cell Physiol Biochem 2017;43:2037-2046 \begin{tabular}{l|l|l} 
DOI: 10.1159/000484184 23, 2017 & $\begin{array}{l}\text { O 2017 The Author(s). Published by S. Karger AG, Basel } \\
\text { www.karger.com/cpb }\end{array}$ \\
and Biochemistry Published online: October
\end{tabular}

to its pathological characteristics, namely papillary carcinoma, follicular adenocarcinoma, medullary thyroid carcinoma, and anaplastic thyroid carcinoma [1]. Although the cause of thyroid cancer is not clear, research advances there have improved understanding of this disease. Regarding thyroid carcinoma, research suggests that morbidity is affected by gender, age, geographical location, race, ionizing radiation exposure, iodine intake, genetics, and sociocultural factors [1-8].

Cysteine-rich intestinal protein (CRIP) belongs to the LIM/double zinc-finger protein family, members of which include cysteine- and glycine-rich protein-1 (CSRP1; MIM 123876), rhombotin-1 (RBTN1; MIM 186921), rhombotin-2 (RBTN2; MIM 180385), and rhombotin-3 (RBTN3; MIM 180386) [9-12]. CRIP1 may be involved in intestinal zinc transport [10, 1315], and is observed to be overexpressed in various types of tumors [16-22] including breast cancer [20, 21], osteosarcoma [19], prostate cancer [17], pancreatic cancer [16], and colorectal cancer [23]. Numerous studies have indicated that CRIP1 is an important transcriptional regulation factor during tumor development. In addition, CRIP1 is highly expressed in the intestine and immune cells, and plays an important role in gut immunity. Porcine CRIP1 is activated by Enterococcus faecalis in porcine gastrointestinal epithelial cells [24].

In the present study, the role of CRIP1 in thyroid carcinoma was investigated. CRIP1 was overexpressed in thyroid carcinoma tissues and cell lines. Furthermore, the relationship between CRIP1 expression and the clinicopathological factors of thyroid carcinoma patients was explored. Lastly, the impact of silencing CRIP1 on cell proliferation, apoptosis, migration, invasion, and cell cycle was assessed. The presented findings provide novel information on the initiation and progression of thyroid carcinoma.

\section{Materials and Methods}

\section{Tissues}

Thyroid carcinoma tissue was obtained from Henan Provincial People's Hospital. All experiments on human subjects were conducted according to the principles of the Declaration of Helsinki. Written informed consent was obtained from all the enrolled participants. This study was approved by the Ethics Committee of the Henan Provincial People's Hospital.

\section{Immunohistochemical staining}

The tissue samples $(n=58)$ were fixed in buffered formalin $(4 \%)$, decalcified using ethylenediaminetetraacetic acid (EDTA), if required, and embedded in paraffin. The resulting blocks were cut into 3- $\mu \mathrm{m}$ sections that were transferred to glass slides and subsequently used for immunohistochemistry. To ensure optimum immunoreactivity in tumor samples, immunohistochemistry for CRIP1 was performed according to the routinely used protocols. Immunohistochemical staining was performed on $3 \mu \mathrm{m}$-thick sections of the tissue microarrays (TMAs) using an automated stainer (Discovery XT) and a DAB Map kit (Ventana Medical Systems, Tucson, AZ, USA). The CRIP1 primary antibody (AbD Serotec, Oxford, UK) was diluted (1:100), and the staining intensities were scored by two independent observers using a 4-point scale as indicated: 0 (no staining) and from $1+$ (light staining) to $3+$ (strong staining).

\section{Cell culture}

The thyrocyte cell line Nthy-ori 3-1, thyroid papillary carcinoma cell line TPC1, and thyroid carcinoma cell lines K1, SW579, and TT were obtained from the Shanghai Cell Institute Country Cell Bank (Shanghai, China). The SW579 and TT cells were grown in DMEM and F12K media, respectively, with $10 \%$ fetal bovine serum (FBS; Gibco BRL, MD) supplemented with $100 \mathrm{U} / \mathrm{mL}$ penicillin G and $100 \mu \mathrm{g} / \mathrm{mL}$ streptomycin (Sigma-Aldrich Corp., St. Louis, MO). The cells were maintained at $37^{\circ} \mathrm{C}$ in a humidified $5 \% \mathrm{CO}_{2}$ incubator.

\section{RNA interference}

Small-interfering RNA (siRNA) oligos for CRIP1 and a general negative control were synthesized and annealed by GenePharma (Shanghai, China). The sequences for CRIP1 siRNA were 5'-GCAACAAGGAGGU- 


\section{Cellular Physiology Cell Physiol Biochem 2017;43:2037-2046 \begin{tabular}{l|l|l} 
and Biochemistry & $\begin{array}{l}\text { DOI 10.1159/000484184 } 2017 \text { The Author(s). Published by S. Karger AG, Basel } \\
\text { www.karger.com/cpb }\end{array}$ \\
\hline
\end{tabular}}

Li et al.: The Impact of CRIP1 on Thyroid Carcinoma

GUACUUTT-3' (sense) and 5'-AAGUACACCUCCUUGUUGCTT-3' (antisense). Each siRNA duplex was transfected into the cells using Lipofectamine ${ }^{\circledR} 2000$ (Invitrogen, Carlsbad, CA, USA) following the manufacturer's protocol.

\section{Quantitative real-time reverse transcription PCR}

For quantitative real-time reverse transcription PCR (qRT-PCR), total RNA was extracted from the cells using TRIzol reagent (Ambion $\AA$ ), as described in the manufacturer's protocol [25]. Next, the RNA samples were reverse transcribed into cDNA using the FastQuant RT kit (with gDNase) (Tiangen, China), in a total volume of $20 \mu \mathrm{L}$, according to the manufacturer's protocol. Equal amounts of cDNA samples were used as a template for real-time PCR to detect the level of CRIP1 gene expression. Glyceraldehyde 3-phosphate dehydrogenase (GAPDH) was used as an endogenous reference gene, and each sample was normalized with respect to the GAPDH level. All experiments were performed in duplicates and repeated twice. Results represent the fold change, calculated using the $2^{-\Delta \Delta C t}$ method. CRIP1 and GAPDH gene primers were as follows. CRIP1-F: 5'-CCTGCCTGAAGTGCGAGAAAT-3', CRIP1-R: 5'-CCTTTAGGCCCAAACATGGC-3'; GAPDH-F: 5'-TGCACCACCAACTGCTTAGC-3', GAPDH-R: 5'-GGCATGGACTGTGGTCATGAG-3'.

\section{Western blot analysis}

Western blot was performed as previously described [25]. Briefly, the proteins were separated by $10 \%$ SDS-PAGE and subsequently transferred onto a nitrocellulose membrane (Bio-Rad). After blocking in 5\% nonfat milk, the membranes were incubated with either anti-CRIP1 (1:300; Abcam) or the rabbit anti-GAPDH polyclonal primary antibody (1:1000; Abcam). The proteins were visualized with enhanced chemiluminescence reagents (Pierce, Rockford, IL, USA).

\section{Cell viability assay}

The 3-(4, 5-dimethylthiazol-2-yl)-2, 5-diphenyltetrazolium bromide assay (MTT) was performed according to the manufacturer's protocol [25]. Briefly, 5, 000 cells/well were plated in triplicate in 96-well plates and allowed to attach overnight. The MTT reagent was prepared at a concentration of $5 \mathrm{mg} / \mathrm{mL} \mathrm{in}$ PBS. This MTT stock solution, at a dilution of 1:10, was added to each well. The cells were incubated for $4 \mathrm{~h}$ and the resulting crystals were dissolved in $100 \mu \mathrm{L}$ DMSO. The absorbance at $490 \mathrm{~nm}$ was measured using a multiwall plate reader.

\section{Apoptosis assay}

The apoptosis assay was performed according to the KGI Annexin V-FITC apoptosis detection kit instruction manual. The SW579 and TT cells were digested with trypsin and centrifuged at 1, $000 \mathrm{rpm}$ for 5 min. After collection, the cells were washed twice with PBS and centrifuged at 1, $000 \mathrm{rpm}$ for $5 \mathrm{~min}$. A total of $5 \times 10^{5}$ cells were collected and resuspended in $500 \mu \mathrm{L}$ binding buffer. Subsequently, $5 \mu \mathrm{L}$ Annexin V-FITC and $5 \mu \mathrm{L}$ propidium iodide (PI) were added, followed by mixing in the dark at room temperature for $15 \mathrm{~min}$. After $1 \mathrm{~h}$, the apoptotic cells were detected by flow cytometry. The excitation wavelength was $488 \mathrm{~nm}$ and the emission wavelength was $530 \mathrm{~nm}$. The green fluorescence of Annexin V-FITC was detected using the FITC channel (FL1) and red fluorescence of PI was detected using the PI channel (FL2 or FL3).

\section{Evaluation of cell cycle}

The SW579 and TT cells were digested with trypsin and centrifuged at 1, $000 \mathrm{rpm}$ for $5 \mathrm{~min}$. After collection, the cells were washed twice with PBS, and centrifuged at 1, $000 \mathrm{rpm}$ for $5 \mathrm{~min}$. Next, the cells were suspended in $70 \%$ ethanol and incubated overnight. A total of $5 \times 10^{5}$ cells were collected and resuspended in $500 \mu \mathrm{L}$ binding buffer. Subsequently, $5 \mu \mathrm{L}$ PI was added, followed by mixing in the dark at room temperature for $30 \mathrm{~min}$. After $1 \mathrm{~h}$, the proportion of cells in different phases of the cell cycle was detected by flow cytometry.

\section{Transwell assay}

Chambers with matrigel and polycarbonate filters (pore size, $8 \mu \mathrm{m}$; Becton Dickinson Labware) were used for the transwell migration assay. Briefly, $24 \mathrm{~h}$ after siRNA transfection, the cells were harvested and $5 \times 10^{4}$ transfected cells resuspended in $200 \mu \mathrm{L}$ medium with $0.1 \%$ serum/FBS were placed in the upper chamber. The lower chamber was filled with $600 \mu \mathrm{L}$ of 10\% FBS-supplemented medium. After 24 
$\mathrm{h}$ of incubation and removal of the cells from the upper chamber of the filter with a cotton swab, the cells on the underside were fixed with $4 \%$ paraformaldehyde, stained with $0.1 \%$ crystal violet in $20 \%$ ethanol, and counted in five randomly selected fields under a phase contrast microscope. The migrated or invasive cells were monitored by imaging at $200 \times$ magnification with a LEICA microscope (Darmstadt, Germany). The assays were performed in triplicates.

\section{Statistical analysis}

Correlations between CRIP1 and the clinicopathological factors were examined using the Spearman's rank correlation test. Data are represented as mean \pm standard deviation (SD), unless otherwise mentioned. The two-tailed Student's $t$-test was used for analyzing the difference between si-CRIP1 and si-NC groups. A $p$-value < 0.05 was considered to be statistically significant.

\section{Results}

Correlation of CRIP1 expression with clinicopathological parameters

The CRIP1 expression profile in thyroid carcinoma was investigated using immunohistochemical staining. CRIP1 expression was considered to be positive when more than $50 \%$ of the tumor cells were immunoreactive for the respective protein (Fig. 1). In total, CRIP1 expression could be evaluated in 58 tissue samples, and was considered to be positive in 46 tissue samples.

Our data suggested that CRIP1 was overexpressed in thyroid carcinoma (Fig. 1 and Table 1), and higher expression

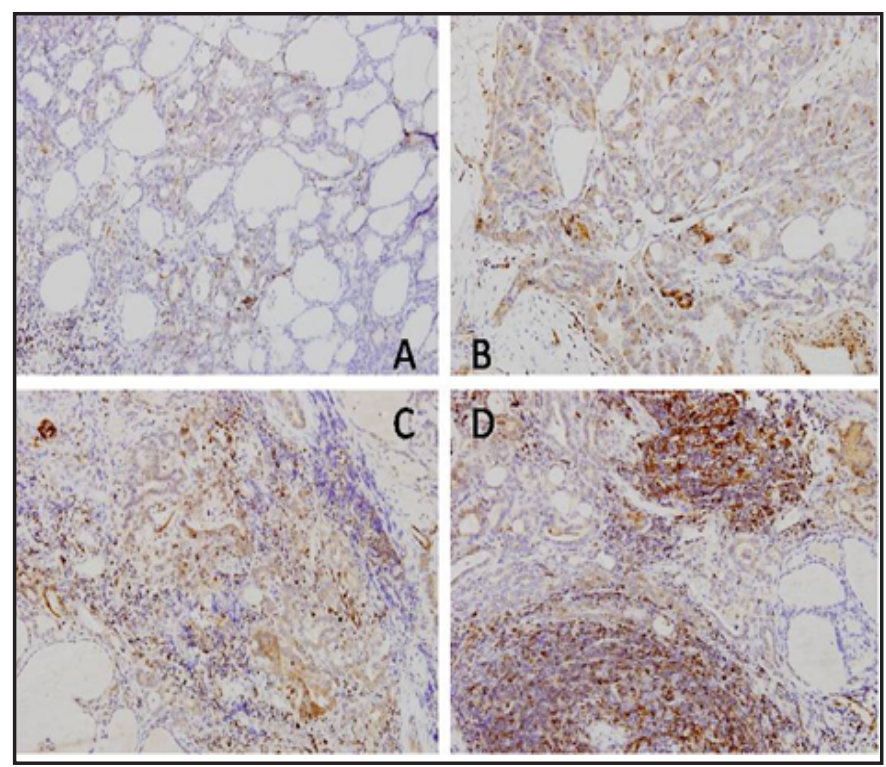

Fig. 1. Expression of cysteine-rich intestinal protein 1 (CRIP1) in thyroid carcinoma tissues. Representative images for immunohistochemical staining of CRIP1 in (A) normal thyroid tissue, and thyroid carcinoma tissue samples showing (B) weakpositive expression ( + ; weak staining pattern), (C) positive expression (++; moderate staining pattern), and (D) strongpositive expression (+++; strong staining pattern). All images were captured at $200 \times$ magnification.

Table 1. Correlation between cysteine-rich intestinal protein 1 (CRIP1) protein expression and the clinicopathological factors of patients with thyroid carcinoma

\begin{tabular}{|c|c|c|c|c|}
\hline \multirow[b]{2}{*}{ Characteristic } & \multirow[b]{2}{*}{ Patients $(\mathrm{n}=58)$} & \multicolumn{2}{|c|}{ CRIP1 expression } & \multirow[b]{2}{*}{ p-value } \\
\hline & & $\begin{array}{l}\text { Positive } \\
(\mathrm{n}=46)\end{array}$ & $\begin{array}{l}\text { Negative } \\
(\mathrm{n}=12)\end{array}$ & \\
\hline Age & & & & 0.910 \\
\hline$<50$ & 25 & 20 & 5 & \\
\hline$\geq 50$ & 33 & 26 & 7 & \\
\hline Gender & & & & 0.358 \\
\hline Male & 27 & 20 & 7 & \\
\hline Female & 31 & 26 & 5 & \\
\hline Location & & & & 0.828 \\
\hline Left lobe & 25 & 19 & 6 & \\
\hline Right lobe & 18 & 14 & 4 & \\
\hline Bilateral & 10 & 9 & 1 & \\
\hline Isthmus & 5 & 4 & 1 & \\
\hline Tumor diameter & & & & 0.022 \\
\hline$<1 \mathrm{~cm}$ & 18 & 11 & 7 & \\
\hline$\geq 1 \mathrm{~cm}$ & 40 & 35 & 5 & \\
\hline TNM stage & & & & \\
\hline I + II & 22 & 13 & 9 & 0.005 \\
\hline $\mathrm{III}+\mathrm{IV}$ & 33 & 30 & 3 & \\
\hline Lymphatic metastasis & & & & 0.003 \\
\hline Negative & 26 & 16 & 10 & \\
\hline Positive & 32 & 30 & 2 & \\
\hline
\end{tabular}
of CRIP1 was associated with tumor size ( $p=0.022)$, TNM stage ( $p=0.005)$, and lymphatic metastasis ( $p=0.003$ ) (Table 1 ). There was no statistically significant correlation observed between the expression of CRIP1 and age ( $p=0.91)$, gender $(p=0.358)$, or tumor location $(p=0.828)$ (Table 1$)$. 


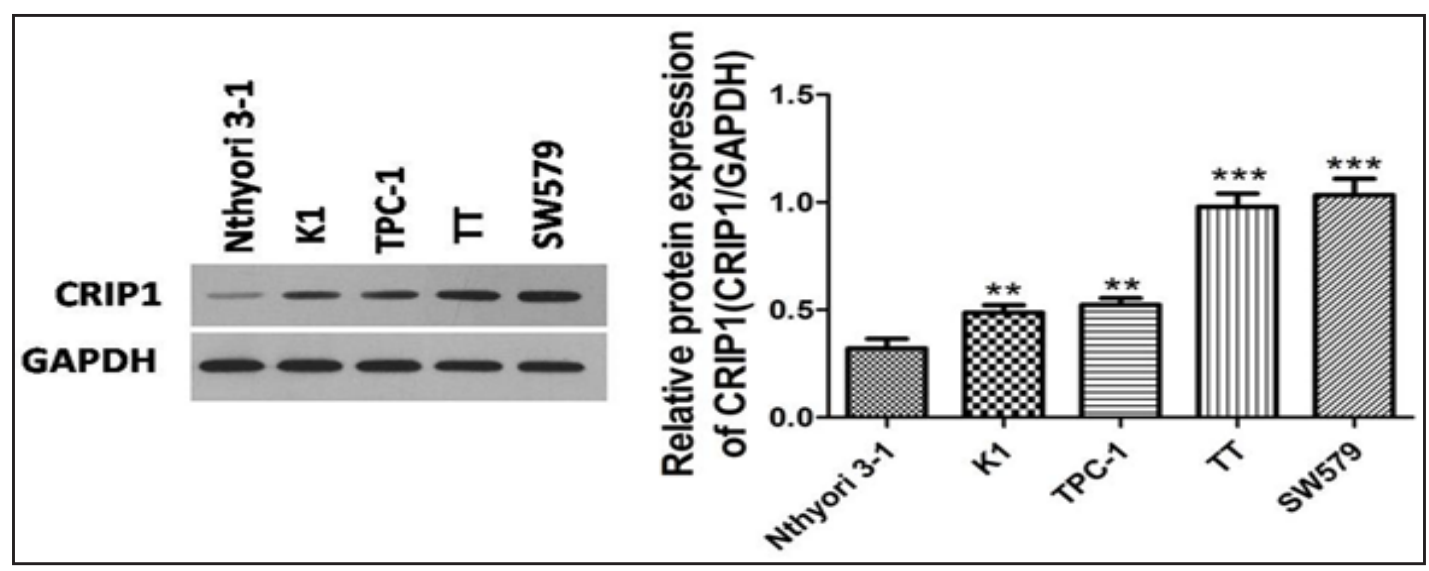

Fig. 2. Expression of cysteine-rich intestinal protein 1 (CRIP1) in thyroid carcinoma tissues and thyrocyte cell lines. Western blotting was performed to examine the protein expression of CRIP1 in thyrocyte cell line Nthy-ori 3-1 and four different thyroid carcinoma cell lines, K1, TPC-1, TT, and SW579. GAPDH was used as the internal control. Right, representative image of the Western blot. Left, intensity analysis for Western blotting data. Data represent mean \pm SD of at least three independent experiments. ${ }^{* *} \mathrm{p}<0.01,{ }^{* * *} \mathrm{p}<0.001$, when compared to Nthy-ori 3-1 group.

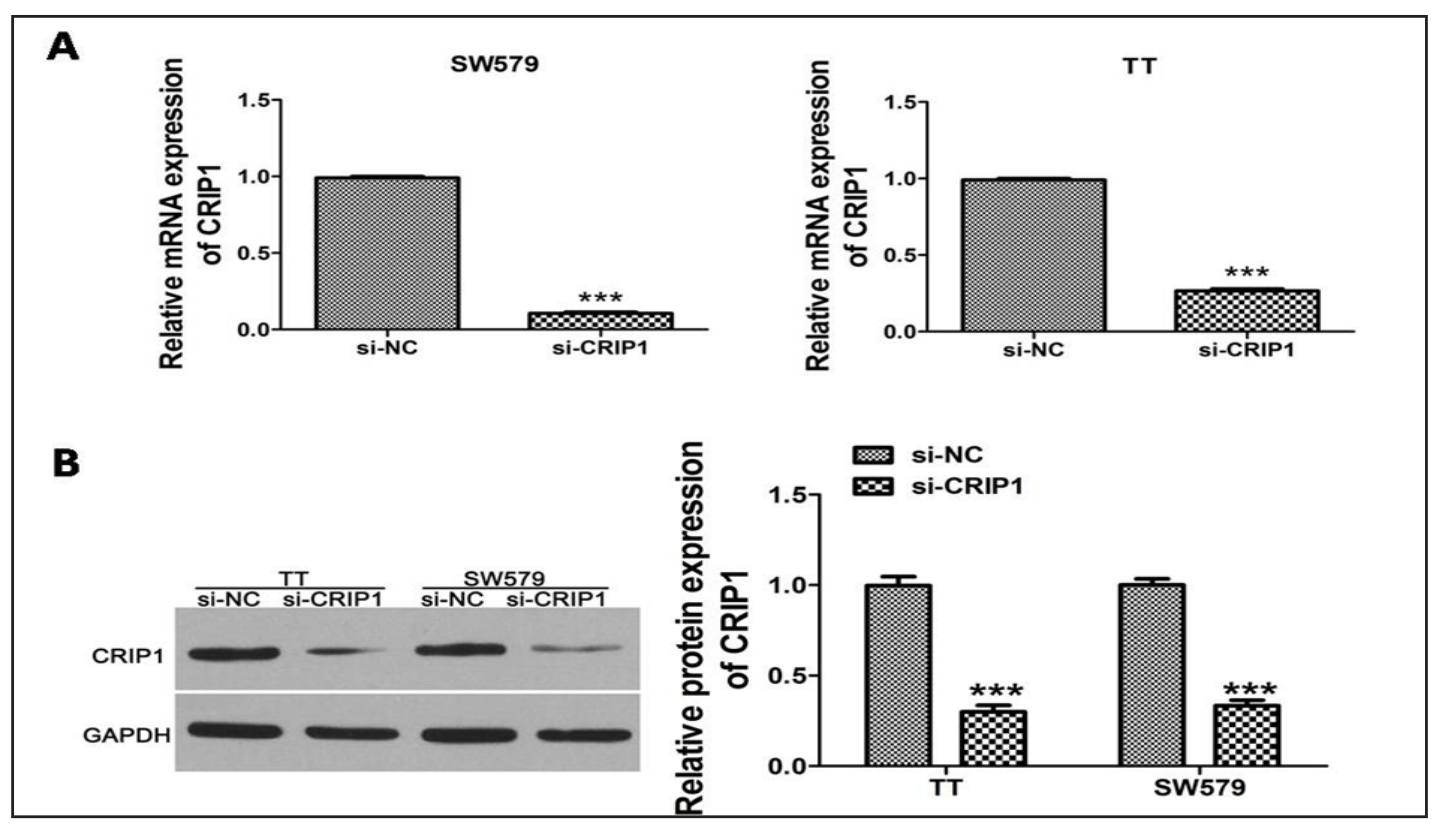

Fig. 3. Silencing efficiency of the siRNA targeting cysteine-rich intestinal protein 1 (CRIP1) expression. The SW579 and TT cells were transfected with si-CRIP1 or si-NC. The endogenous expression of CRIP1 was examined by qRT-PCR (A) and Western blotting (B). GAPDH was used as the internal control for qRT-PCR and Western blotting. Data represent mean \pm SD of at least three independent experiments. ${ }^{* * *} \mathrm{p}<0.001$.

Overexpression of CRIP1 in thyroid carcinoma cell lines

Western blot was performed to investigate CRIP1 protein expression in the thyrocyte cell line Nthy-ori 3-1, and four different thyroid carcinoma cell lines, K1, TPC-1, TT, and SW579. GAPDH was used as an internal control. Expression of CRIP1 in K1, TPC-1, TT, and SW529 cells was higher than that in the Nthy-ori 3-1 cells. The highest expression was observed in the SW579 and TT cells (Fig. 2).

\section{KARGER}




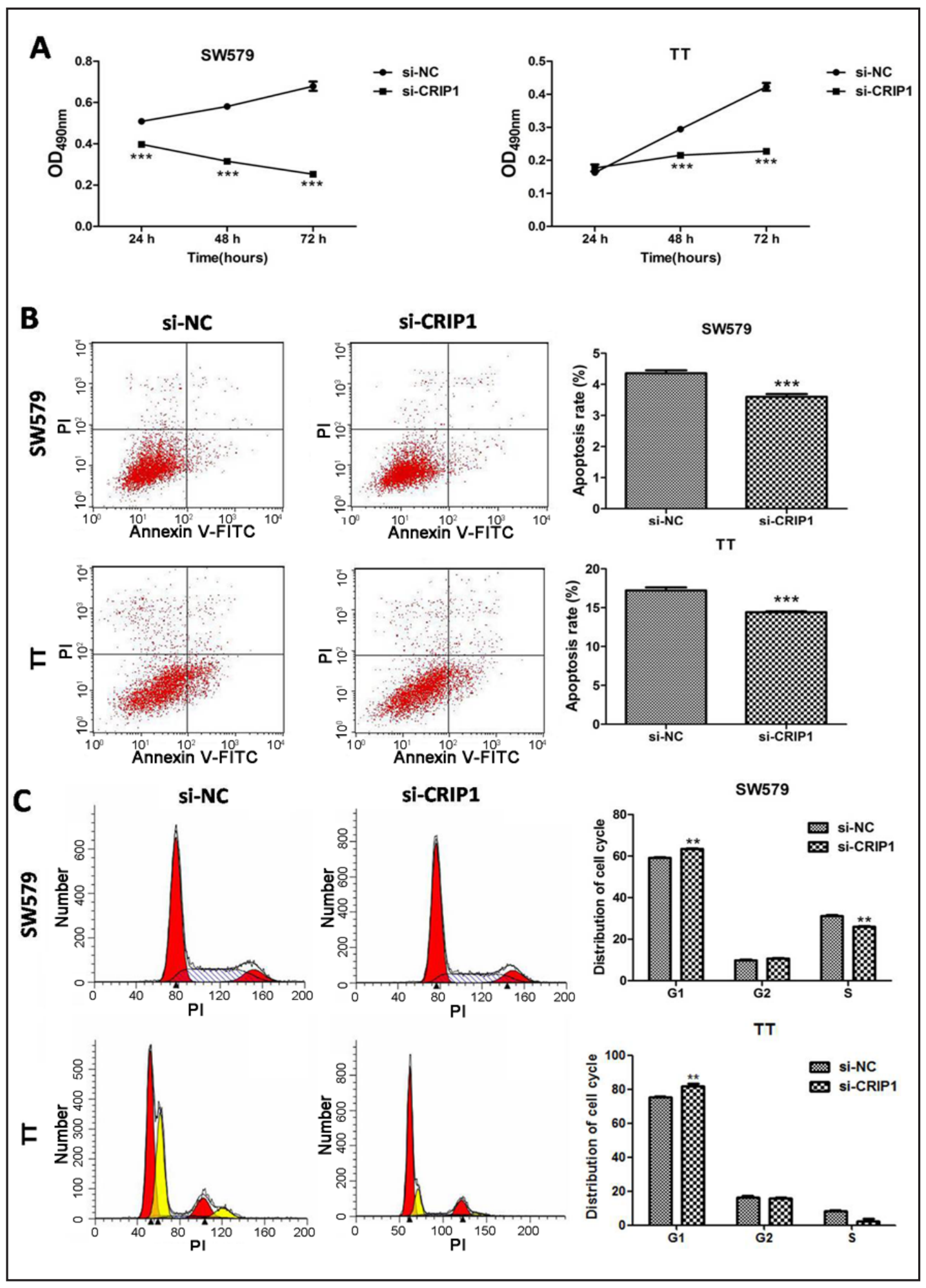

Fig. 4. The effects of silencing cysteine-rich intestinal protein 1 (CRIP1) on proliferation, cell cycle, and apoptosis in thyroid carcinoma cells. (A) Cell viability assay for the SW579 and TT cells. (B) Apoptosis assay for the SW579 and TT cells. (C) Cell cycle assay for the SW579 and TT cells. The SW579 and TT cells were transfected with si-CRIP1 or si-NC. Data represent mean \pm SD of at least three independent experiments. ${ }^{* *} \mathrm{p}<0.01,{ }^{* * *} \mathrm{p}<0.001$. 


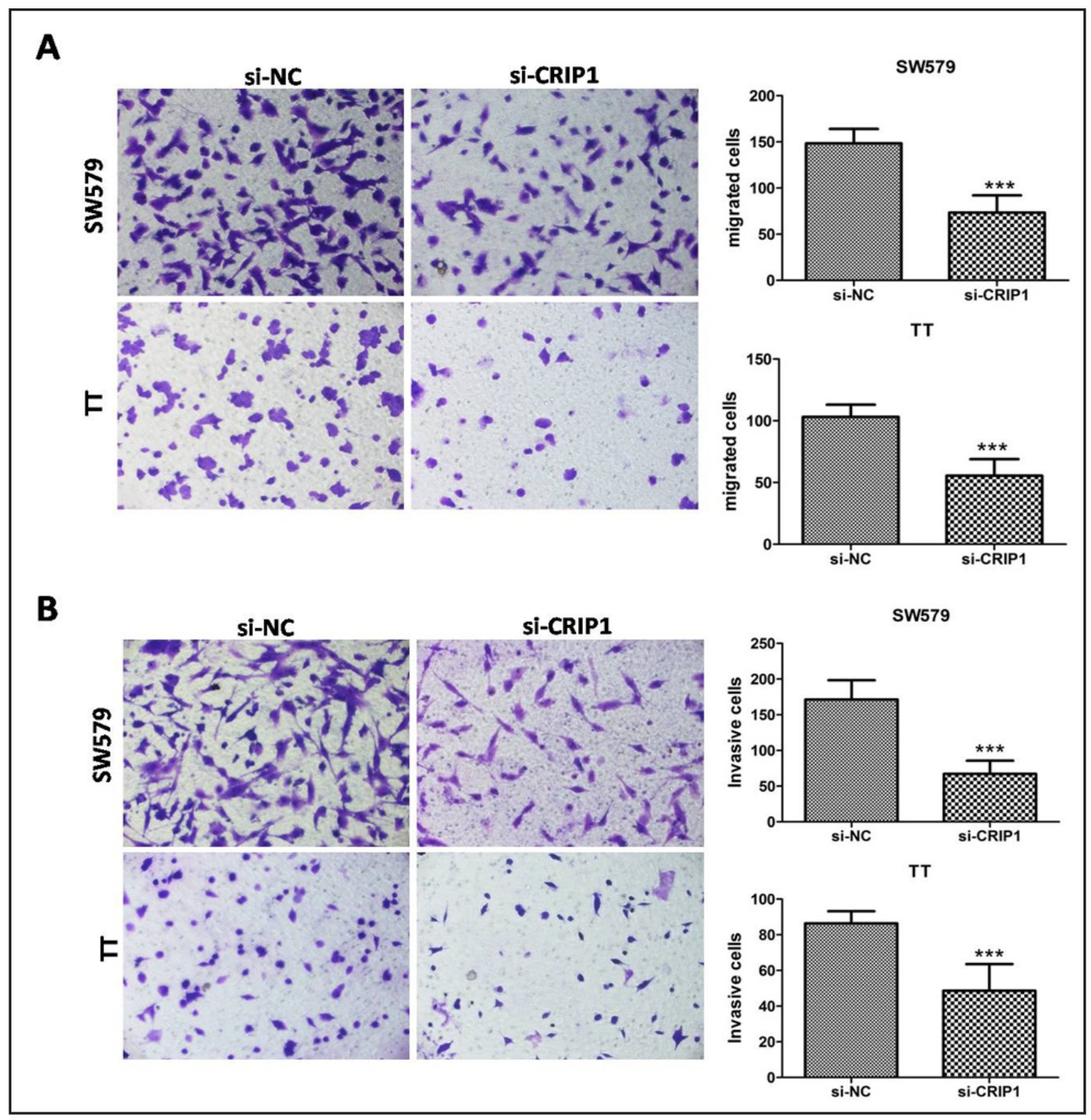

Fig. 5. The effects of silencing cysteine-rich intestinal protein 1 (CRIP1) on migration and invasion of the thyroid carcinoma cells. The SW579 and TT cells were transfected with si-CRIP1 or si-NC. The migration (A) and invasion (B) of SW579 and TT cells were evaluated using the transwell assays. Images are shown at their original magnification $(200 \times)$. Data represent mean \pm SD of at least three independent experiments. $* * * \mathrm{p}<0.001$.

Silencing CRIP1 inhibits cell proliferation and induces apoptosis and G1 arrest

Since CRIP1 was found to be overexpressed in the thyroid carcinoma tissues, the endogenous expression of CRIP1 was suppressed and the effects of low CRIP1 expression on cell proliferation, apoptosis, migration, invasion, and cell cycle were investigated in the SW579 and TT cells, the cell lines with the highest CRIP1 expression.

Specifically, the endogenous expression of CRIP1 was suppressed using a siRNA (siCRIP1) that targeted the position $134 \mathrm{bp}$ of the CRIP1 mRNA. Scrambled siRNA was used as the negative control (si-NC). The silencing efficiency of si-CRIP1 was determined by qRT-PCR and Western blotting (Fig. 3).

Cell viability was evaluated using the MTT assay. Cell apoptosis and cell cycle were evaluated by flow cytometric analysis. A notable decrease in the viability of SW579 and TT 
cells transfected with si-CRIP1 was observed (Fig. 4A). This suggested that the silencing of CRIP1 inhibited the proliferation of thyroid carcinoma cells. The data obtained from flow cytometry showed increased apoptosis in the SW579 and TT cells transfected with si-CRIP1 (Fig. 4B). This suggested that silencing of CRIP1 enhanced apoptosis in the thyroid carcinoma cells. The cell cycle evaluation showed a significant increase in the G1 phase for the SW579 and TT cells transfected with si-CRIP1 (Fig. 4C). This result suggested that silencing of CRIP1 induced G1 arrest in thyroid carcinoma cells.

\section{Silencing CRIP1 inhibits cell migration and invasion}

We investigated the effects of silencing CRIP1 on the migration and invasion of thyroid carcinoma cells using the transwell assay. Decreased migration and invasion abilities were observed for the SW579 and TT cells transfected with si-CRIP1 in comparison with those transfected with si-NC (Fig. 5A and B). This result suggested that silencing of CRIP1 inhibited the migration and invasion of thyroid carcinoma cells.

\section{Discussion}

In this study, we report that CRIP1 is overexpressed in the thyroid carcinoma tissues and cell lines. Higher expression of CRIP1 was associated with tumor size, TNM stage, and lymphatic metastasis. However, the expression of CRIP1 was not associated with age, gender, or tumor location. In addition, knockdown of CRIP1 expression inhibited the proliferation, migration, and invasion, and induced G1 arrest and apoptosis in the thyroid carcinoma cells.

Several studies have indicated that CRIP1 is involved in few types of cancers, including osteosarcoma [19], breast cancer [20], endometrial cancer, [22] and prostate cancer [17]. However, the role of CRIP1 is not conclusively reported in these cancers. A few studies suggest that CRIP1 functions as an oncogene. Lambropoulou et al. showed that higher expression of CRIP1 is associated with shorter survival times in endometrial cancer [22]. Our data supports the oncogenic role of CRIP1. In the present study, CRIP1 was overexpressed in the thyroid carcinoma cells, and its expression was found to be associated with tumor size, TNM stage, and lymphatic metastasis. Moreover, in vitro silencing of CRIP1 inhibited proliferation, migration, and invasion, and induced G1 arrest and apoptosis in the thyroid carcinoma cells. These results suggested that CRIP1 functions as an oncogene in thyroid carcinoma.

In contrast, a few studies indicate that CRIP1 may function as a tumor suppressor. Baumhoer and colleagues showed that CRIP1 expression is correlated with a favorable outcome and less metastasis in patients with osteosarcoma [19]. Ludyga et al. showed that the lack of CRIP1 expression in breast cancer tissues was significantly associated with a poor prognosis for patients [20]. Furthermore, low endogenous CRIP1 levels increased the malignant potential of breast cancer cells in vitro [20]. These results indicate that CRIP1 may act as a tumor suppressor during the proliferation and invasion processes. Therefore, CRIP1 may be an independent prognostic marker with significant predictive power for use in breast cancer therapy [20].

In conclusion, since the lack of CRIP1 expression in thyroid carcinoma tissues was significantly associated with a poor prognosis for patients and low endogenous CRIP1 levels increased the malignant potential of thyroid carcinoma cells in vitro, we hypothesize that CRIP1 may act as an oncogene during the proliferation and invasion processes. Therefore, CRIP1 could be an independent prognostic marker with significant predictive power for use in thyroid carcinoma therapy.

\section{Acknowledgements}

This work was supported by the Henan Provincial Department of Science and Technology Foundation (grant number 132300410367). We thank Editage (http://www.editage.cn/) for its linguistic assistance during the preparation of this manuscript. 


\section{Cellular Physiology Cell Physiol Biochem 2017;43:2037-2046

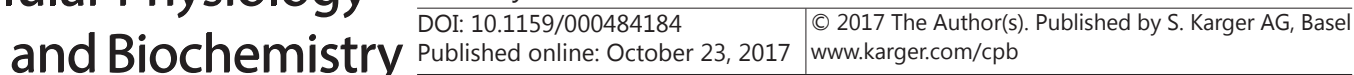 \\ Li et al.: The Impact of CRIP1 on Thyroid Carcinoma}

\section{Disclosure Statement}

The authors declare that they have no competing interests.

\section{References}

1 Guerrero R: Carcinoma of the Thyroid: Epidemiology, Diagnosis, and Treatment. Asian Am Pac Isl J Health 1998;6:248-249.

-2 Busnardo B, De Vido D: The epidemiology and etiology of differentiated thyroid carcinoma. Biomed Pharmacother 2000;54:322-326.

-3 Romanchishen AF, Bagaturiia GO, Gostimskii AV, Bagatikov AA: Epidemiology and specificity of thyroid carcinoma clinical course before and after the Chernobyl accident. Vestn Khir Im I I Grek 2010;169:68-72.

-4 Tran Cao HS, Johnston LE, Chang DC, Bouvet M: A critical analysis of the American Joint Committee on Cancer (AJCC) staging system for differentiated thyroid carcinoma in young patients on the basis of the Surveillance, Epidemiology, and End Results (SEER) registry. Surgery 2012;152:145-151.

5 Raue F, Frank-Raue K: Epidemiology and Clinical Presentation of Medullary Thyroid Carcinoma. Recent Results Cancer Res 2015;204:61-90.

6 Deng X, Wu B, Xiao K, Kang J, Xie J, Zhang X, Fan Y: MiR-146b-5p promotes metastasis and induces epithelial-mesenchymal transition in thyroid cancer by targeting ZNRF3. Cell Physiol Biochem 2015;35:7182.

7 Xu B, Shao Q, Xie K, Zhang Y, Dong T, Xia Y, Tang W: The Long Non-Coding RNA ENST00000537266 and ENST00000426615 Influence Papillary Thyroid Cancer Cell Proliferation and Motility. Cell Physiol Biochem 2016;38:368-378.

8 Leenhardt L, Grosclaude P: Epidemiology of thyroid carcinoma over the world. Ann Endocrinol (Paris) 2011;72:136-148.

-9 Jurata LW, Kenny DA, Gill GN: Nuclear LIM interactor, a rhombotin and LIM homeodomain interacting protein, is expressed early in neuronal development. Proc Natl Acad Sci U S A 1996;93:11693-11698.

10 Perez-Alvarado GC, Kosa JL, Louis HA, Beckerle MC, Winge DR, Summers MF: Structure of the cysteine-rich intestinal protein, CRIP. J Mol Biol 1996;257:153-174.

11 Jurata LW, Gill GN: Functional analysis of the nuclear LIM domain interactor NLI. Mol Cell Biol 1997;17:5688-5698.

12 Jurata LW, Pfaff SL, Gill GN: The nuclear LIM domain interactor NLI mediates homo- and heterodimerization of LIM domain transcription factors. J Biol Chem 1998;273:3152-3157.

13 Birkenmeier EH, Gordon JI: Developmental regulation of a gene that encodes a cysteine-rich intestinal protein and maps near the murine immunoglobulin heavy chain locus. Proc Natl Acad Sci U S A 1986;83:2516-2520.

14 Hempe JM, Cousins RJ: Cysteine-rich intestinal protein binds zinc during transmucosal zinc transport. Proc Natl Acad Sci U S A 1991;88:9671-9674.

15 O'Dell BL: Cysteine-rich intestinal protein (CRIP): a new intestinal zinc transport protein. Nutr Rev 1992;50:232-233.

16 Terris B, Blaveri E, Crnogorac-Jurcevic T, Jones M, Missiaglia E, Ruszniewski P, Sauvanet A, Lemoine NR: Characterization of gene expression profiles in intraductal papillary-mucinous tumors of the pancreas. Am J Pathol 2002;160:1745-1754.

17 Wang Q, Williamson M, Bott S, Brookman-Amissah N, Freeman A, Nariculam J, Hubank MJ, Ahmed A, Masters JR: Hypomethylation of WNT5A, CRIP1 and S100P in prostate cancer. Oncogene 2007;26:65606565.

18 Hao J, Serohijos AW, Newton G, Tassone G, Wang Z, Sgroi DC, Dokholyan NV, Basilion JP: Identification and rational redesign of peptide ligands to CRIP1, a novel biomarker for cancers. PLoS Comput Biol 2008;4:e1000138.

19 Baumhoer D, Elsner M, Smida J, Zillmer S, Rauser S, Schoene C, Balluff B, Bielack S, Jundt G, Walch A, Nathrath M: CRIP1 expression is correlated with a favorable outcome and less metastases in osteosarcoma patients. Oncotarget 2011;2:970-975. 


\section{Cellular Physiology Cell Physiol Biochem 2017;43:2037-2046

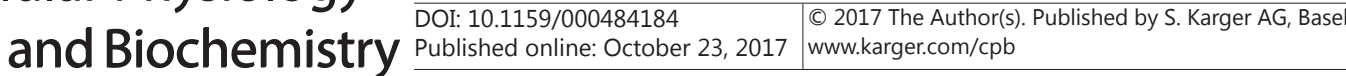 \\ Li et al.: The Impact of CRIP1 on Thyroid Carcinoma}

20 Ludyga N, Englert S, Pflieger K, Rauser S, Braselmann H, Walch A, Auer G, Hofler H, Aubele M: The impact of cysteine-rich intestinal protein 1 (CRIP1) in human breast cancer. Mol Cancer 2013;12:28.

21 Xie H, Li H, Huang Y, Wang X, Yin Y, Li G: Combining peptide and DNA for protein assay: CRIP1 detection for breast cancer staging. ACS Appl Mater Interfaces 2014;6:459-463.

-22 Lambropoulou M, Deftereou TE, Kynigopoulos S, Patsias A, Anagnostopoulos C, Alexiadis G, Kotini A, Tsaroucha A, Nikolaidou C, Kiziridou A, Papadopoulos N, Chatzaki E: Co-expression of galectin-3 and CRIP1 in endometrial cancer: prognostic value and patient survival. Med Oncol 2016;33:8.

-23 Groene J, Mansmann U, Meister R, Staub E, Roepcke S, Heinze M, Klaman I, Brummendorf T, Hermann K, Loddenkemper C, Pilarsky C, Mann B, Adams HP, Buhr HJ, Rosenthal A: Transcriptional census of 36 microdissected colorectal cancers yields a gene signature to distinguish UICC II and III. Int J Cancer 2006;119:1829-1836.

-24 Cai H, Chen J, Liu J, Zeng M, Ming F, Lu Z, Cheng Q Yang J, Zhang L: CRIP1, a novel immune-related protein, activated by Enterococcus faecalis in porcine gastrointestinal epithelial cells. Gene 2017;598:84-96.

25 Huang H, Jiang Y, Wang Y, Chen T, Yang L, He H, Lin Z, Liu T, Yang T, Kamp DW, Wu B, Liu G: miR-5100 promotes tumor growth in lung cancer by targeting Rab6. Cancer Lett 2015;362:15-24. 